\title{
Public Policies from the Professionalization of Psychology in Argentina to the Mental Health Law (1954 - 2010)
}

\section{Campodonico $\mathrm{N}^{*}$}

National University of La Plata, Argentina

*Corresponding author: Nicolás Campodónico, National University of La Plata, $10 \mathrm{~N}$

1885 La Plata, Argentina, Tel: 221 6541199; Email:

\section{Research Article}

Volume 3 Issue 4

Received Date: April 25, 2018

Published Date: May 25, 2018

nicolas_campodonico@hotmail.com

\section{Abstract}

At present, new historical conditions make Mental Health a topic of growing concern both at the level of public policy and theoretical orientations. In the context of current changes, social policies, and health policies in particular, are transformed into the redefinition of the functions of the State. For this reason, we intend to analyze the avatars and social, political, cultural and economic contexts, through which the formulations and applications of public policies in mental health have gone through in the history of Argentina, taking as a period from: the professionalization of the Psychology from 1954 until the formulation of the Mental Health Law in 2010. To thus historicize the vicissitudes and implications that arose in this period. Thus history helps us with what is presented as conflicting within our field, but also what appears as unquestionable.

Keywords: Mental Health; Public Policy; Cultural Influence; History

\section{Introduction}

In the context of current changes, social policies, including health policies in particular, are severely transformed in the redefinition of State functions. Practices in mental health are, obviously, traversed by these policies that generate concerns and occupations, analysis and reflections and involve movements and constant transformations in that field. We thought it important to start from the reference of the authors regarding the consideration of mental health practices as a simultaneous set of representations, knowledge and specific actions of a defined field, mental health, nonhomogeneous space, contradictions and antagonisms. Thus, the field of mental health becomes a sub-field of health practices in general, whose specificity is defined by the particular social construct of meaning with respect to the madness produced in modernity, and its specific institutional forms [1]. The configuration of the field of mental health can be characterized as a process that was given through the passage from an asylum-asylum model to the important policies in the field of mental health that are currently being developed. These policies on mental health in turn raise the issue of the path from the tutelary paradigm to the paradigm of human rights [2].

In view of the criticism of the asylum-asylum system, the generation of diverse assistance proposals, it is possible to be located in the early fifties in the last century, linked, on the one hand, to the establishment of 


\section{Psychology \& Psychological Research International Journal}

the Social State in the central countries, and on the other, later, to the social movements tending to question ruling orders. The redistribution operated by social policies at that time tended to provide margins of health and welfare to the population and to maintain the limits of social conflicts within the domain of technical-administrative knowledge. We can mention that most of the transformations in mental health were included in more extensive health reforms. Such is the case of English community psychiatry, the Italian Psychiatric Reform, among others. However, with the exception of the Italian experience, all these experiences end up coexisting with asylums and, in some cases, seeing the reappearance of objectifying and segregate assumptions within supposedly innovative practices.

\section{Psychopathology and the Field of Mental Health}

It is necessary to state the coordinates of the emergence of psychiatry, which is born as a branch of medicine in order to respond to a demand of epoch consequent to the birth of modern states. This is what Michel Foucault (1967) conceptualized about his political birth in the context of the French Revolution [3]. In a city designed to roam free citizens in public spaces, and in a society that assumed that subjects ruled by reason made the necessary choices to position themselves freely and individually, it was necessary to define a material and symbolic space to house to "madness" and to protect those who could not exercise freedom because they were "alienated".

It was supposed a society composed of rational subjects that made decisions based on the maximum benefit at the lowest cost and that was developed harmonically by the engine of market competition. The State was the guarantor of compliance with this contract and should also define the spaces for those who were disruptive within this scheme. Hence the birth of welfare institutions founded on philanthropic logic, and sustained in an articulation between science and morality. In this context, the new branch of medicine, "mental" medicine, instituted what were formerly prisons as healing spaces. The deprivation of rights, in the institution of guardianship, happened to be disguised by the assumption of care or healing. In this regard Emiliano Galende (1990) says: "the great change in therapeutic practices is introduced by the medicalization of the care relationship, going from what was a compulsory and police confinement with validation of the Church to a compulsive treatment of the sick" [4]. In this confluence, the asylum-asylum institution that will be the paradigm of the medicalization of madness is consolidated. We can situate that, in the first place, in a beginning "the madman" was in charge of the legal discourse who made a social and non-therapeutic approach, placing it next to the marginal, criminal, among others, constituting in this way an undifferentiated group that attempted against the material and social order of the family and the State. All this under the paradigm of danger.

The presence of medicine in the treatment of madness, allowed extracting the madman from this group, to provide a category outside the social and legal discourse. It is necessary to clarify, in this point, that medicalization was not exclusive to psychiatry. It is a facet of a process in which modern science, which supposedly produces an objective and true knowledge, external to the interests and optics of the various social subjects, was instituted as a reason for power, replacing the place of religion. Positivism as a hegemonic thought raised science as guarantor of the rationality of social order. In that precise place, medicine was called to exercise a computer role in the name of the good of the subjects and the development of society. At the beginning of the 20th century, this model began to be questioned by nascent mental hygiene. In this way we see that the concept of "mental health field", so important today, has its particular history. It is located as an inheritor of hygienism, a movement that aimed to prevent the various health problems in the social set.

Mental Hygiene emerged as a movement at a moment and in a certain place: at the beginning of the 20th century in the United States. Its protagonists sought to change the situation of therapies, hospitals and patients hospitalized in asylum institutions, emphasizing the need for prevention. This hygienism was opposed to alienism and the monopoly of the answers given by psychiatry and its institution, the asylum. The transformations of psychiatry under the influence of hygienism are described by Leo Kanner: "what used to be considered a circumscribed pathological entity was now regarded as the harmful activity of a person, sometimes of recognized organic foundation, often without that etiology but always impregnated by personality factors and the environment. Psychiatry left the insane asylums, divorced from the restrictions imposed on the legal concept of insanity, confinement and devoted itself to attending all kinds of defective human behavior, of any intensity. Although the mental hygienism criticized the conditions of the asylum model, it did not manage to modify the principles of deprivation of rights or the model of the seclusion that characterized it [5]. However, we can say that it took the 


\section{Psychology \& Psychological Research International Journal}

first steps to open the perspectives of the practices traditionally circumscribed to asylum. Despite this, in the second half of the twentieth century, in the postwar period, the processes of psychiatric reform began within the framework of the birth of public policies on mental health.

Although mental hygienism criticized the conditions of the asylum model, it did not manage to modify the principles of deprivation of rights or the model of seclusion that characterized it. However, we can say that it took the first steps to open the perspectives of the practices traditionally circumscribed to asylum. Despite this, only in the second half of the twentieth century, in the postwar period, the processes of psychiatric reform began within the framework of the birth of public policies on mental health. It is from the crisis of the 1930s, with the reformulation of the State under the influence of Keynesianism that will be generated, for practices and conceptions in health, a context of profound transformations with the birth of universal social policies, in replacement of the philanthropy of the liberal states. For the purposes of this work, health policies matter and mental health policies are related to them. The Social or Welfare States had their greatest development in the central countries in the period from the post-war period to the crisis of the mid-1970s. (Stolkiner, 2003-2004) This new conception of the State and of rights is directly reflected in the definition of health that the World Health Organization (WHO) states at its birth in 1948 [6,7]: "Health is a state of complete well-being: physical, mental and social, and not only the absence of disease." It is a definition that proposes to assume health as a complex object and as a social responsibility. So we can point out in this definition that it would be about seeing health as a welfare state, complete, effective and efficient.

About this process, says Galende (1990): "in the fifties the new reordering of the mental in the world is being defined. Goffman shows in the United States the creation of a new pathology due to internment. The sociotherapies and the therapeutic communities grow throughout the North American territory. When the Kennedy Law arrived in 1963, with the Federal Program of Community Psychiatry, the land was abandoned. In France, from Saint-Alban and with the support of the Patriotic Front, health reform is promulgated and the creation of the sector as a new policy in Mental Health. In Italy, the Democratic Front, rebuilds the health organization and installs the first therapeutic communities, then, with Basaglia, lead to the closure of the Trieste Hospital and the current mental health law. All this movement should not be understood as the deployment, extension or modernization of psychiatry, since; on the contrary, it constitutes its crisis, expressed precisely in its institutional image, and must lead to the construction of a new model of action, which are mental health policies [4].

Mental health policies were as diverse as the contexts and states in which they were developed. However, there are some trends that, in general terms, can be indicated as implicit or desirable in the reform proposals:

1. Focus attention on the concept of mental suffering or subjective suffering and not mental illness.

2. Break the assumption or representation of danger associated with seclusion. Modify the legal rules in this regard.

3. Propose outpatient or integrated forms to the society of attention of traditional psychiatric pathologies.

4. Work on the social production of subjective suffering in the spheres of social life community in health promotion activities.

5. Incorporate the conceptualization of citizenship and rights as a component of curative and preventive practice.

6. Recognize that the complexity of the problem implies an interdisciplinary approach and intersectorial.

In recent times, new conditions and historical conceptions make mental health a topic of growing concern and occupation. In line with this reality, the International Mental Health Conference was held in 1996, and the final document of that meeting, in accordance with the general trend in health, highlighted the need to reorient efforts from the institutional to the community level, and to include mental health services in health insurance programs. In addition, the creation of programs designed to ensure the social development of children and the rights of people with mental disabilities was stimulated. 2002 is declared by the WHO International Year of Mental Health and as part of it the World Program of Action on Mental Health was announced. In our country, in the Federal Health Plan 2004-2007 structured according to the Primary Health Care, the Ministry of Health of the Argentine Republic considers Mental Health as one of the important areas on which it is necessary to implement actions specific but denounces at the same time "the lack of information to establish baselines in some of the main health problems and risk factors in Argentina [8]. In this way and in accordance with the importance of attending to this field that is becoming more and more important, the implementation of programs and plans in the field of mental health is intensifying since the so-called Primary Care. 


\section{Psychology \& Psychological Research International Journal}

A certain approach to the theoretical proposals on Primary Care allows us to think that there is currently no univocal definition of the term. There are different meanings, conditioned by the different theoretical approaches of the health disciplines that implement it. From a certain perspective, one thinks then, the work in this level of attention as carried out by different professionals who work the health problems from interdisciplinary teams, being its objective the integral attention of the problems that the community and the subjects that compose it present However, a differentiation of prevention of health care based on three levels: primary, secondary and tertiary. Primary Health Care aims to promote and protect the health of the population, a way to anticipate the disease from preventive actions. Among them are Health Education, Immunization and Environmental Sanitation. It is carried out essentially in the Health Centers of the Programmatic Area and the Services of Promotion and Protection of the Health of the public hospitals. It constitutes the first level of health care. Secondary Health Care is represented by the ambulatory care of patients in outpatient clinics, even in cases that require clinical and / or surgical hospitalization of common pathologies. It constitutes the second level of health care. Tertiary Health Care is the level of maximum medical complexity, either due to the pathology that patients present, as well as the necessary diagnostic and treatment technical resources. They are patients who are admitted to Intensive Care Units and / or Coronary Unit, as well as other services such as Neurosurgery. It constitutes the third level of health care.

In this sense, Primary Health Care (PHC) is a strategy defined at the Alma Ata conference in 1978, where an advance was established to overcome biomedical models, focused on the disease that privilege expensive, curative services in establishments of second and third level by models based on the promotion of health and preventive of the disease at reasonable costs for the population. It is there that Primary Health Care was defined as: "essential health care, based on scientifically founded and socially acceptable methods and practical technologies, made available to all individuals in the community, through their full participation and at a cost that the community and the country can support each and every one of the stages of its development, in a spirit of self-responsibility and self-determination ". (WHO, 1978) Analyzing the concept of PHC, Yamila Comes states that "international organizations only postulate broad and often diffuse definitions [9]. The way in which each government interprets what is the Primary Health Care makes the Public Health model in which it is registered ". (Stolkiner,
1999) Other authors think the work in Primary Care from a different perspective. One of the criteria is equality in the quality of care (Galende, 1990); This means that working at this level of care is not only "the gateway to the health system, nor is it medicine for the poor" (Galende, 1990, p.222), but it means assuring health coverage to all citizens of the territory regardless of their social class. It is about the coverage being for everyone. This approach to the theoretical proposals on Primary Care allows us to think that there are different meanings, conditioned by the different theoretical approaches typical of the health disciplines that implement it [4].

Therefore, we can recognize that each epoch has a particular form of suffering production and of responding to them as well. Following this idea, Galende (1992) states, as a hypothesis that in the current conditions it is expected a growth of what is encompassed under the name of narcissistic pathologies: character disorders, perversions, functional diseases, psychosomatic disorders and addictions, as well as an increase in family violence and suicides [10]. In conjunction with the increase of depressions of various kinds. However, some of these problems were already relevant and their apparent increase in relative terms may come from their exit from a space of social invisibility. The clearest example is that of mistreatment of women, their increase cannot be assessed by the demand for assistance. As an epidemiological indicator, the demand is of little value given that until a few years ago there were no services that would provide assistance to this problem and it was consensually located in the sphere of the intimate, not transcending the domestic space. Perhaps the modifications of representations of gender and women's situation tend to facilitate their shift of the domestic and intimate sphere and favor the emergence of the same in the public sphere. Perhaps one of the effects of the crisis is to make situations more transparent, to de-disseminate processes and to challenge theoretical revisions in order to adjust the tools to the problems. Probably it is necessary to think about new categorizations in function of the new forms of production of suffering. In these new categorizations, the diffuse (and eventually asymptomatic) malaise of the crisis of the institutions cannot be left out [10].

For mental health policies, the objectives and foundational formulations are maintained, enriched with the advances in the experiences of their achievements and the conceptual and doctrinal refinement in the various disciplines and perspectives that are integrated in the field of mental health. Among them, those that have had a 


\section{Psychology \& Psychological Research International Journal}

significant development in these decades are those that are driven by jurisprudence and policies that have to do with human and social rights. Although from the principles of mental health was denounced and fought against segregation and violence exercised on the "crazy" and their families, or on alcoholics or drug problems, is simultaneously with the global and national increase in fighting for those rights that begin to make visible the problems of mental suffering and their cultural ways of inhuman treatment as a problem that must necessarily be seen as a violation of fundamental rights. With this, legal frameworks were produced in accordance with numerous principles, agreements, international declarations and recommendations of international organizations, to which our country adhered and which in some of them collaborated in drafting, committing to use them as guides for the planning of public policies.

\section{Psychiatry in Argentina}

In 1854 the Hospicio de Mujeres was created, today "Braulio Moyano" and in 1863 that of Men, now Hospital "José T. Borda", in the city of Buenos Aires. Framed in a vision of individualistic health, sustained by the initiative and the gift of charitable societies and often directed by confessional powers. In the case of the first asylums, in a short time they reflected images of great imprisonment, neglecting the special conditions with which the alienist had to produce the so-called "moral treatment".

This situation was partially alleviated by the alienist Domingo Cabred who created the National Colony of Aliens "Open Door" in 1899, and in 1906 the Directorate of the Commission of Asylums and Regional Hospitals. In 1920, Cabred promoted the construction of numerous colonies and asylums, and carried out a series of reforms that were in the intentions of some progressive alienists. Cabred intended to extend this system (Open Door) to all types of alienated and stressed that the role of the colony asylums was to provide assistance and education. Practically there were no leaks, due to the well-being he had in the sick. He argued the importance of a treatment where the patient developed varied tasks in the open air, with the greatest amount of freedom compatible with his condition and with the possibility of also performing a number of complementary tasks that channel work skills [11].

However, the transformations of the country's social situation compromised this panorama. The agro-export model and the promotion of immigration implied a displacement of population to the cities, which grew rapidly and produced new social and health problems. In this way, the nascent ideas of "Hygienism" were incorporated, which aimed to prevent the various health problems (from epidemics to crimes) in the social set.

In the following decades there was a transition that was undressing the limits of the policies of alienists and hygienists due to structural indigence, typical of the logic of the asylum; and by the chronic insufficiency of resources denied by the ruling classes. In 1931 the prominent psychiatrist Gonzalo Bosch published a text on "The terrible aspect of madness in the Argentine Republic", in which he criticized a failed state, a crisis of legitimacy in psychiatry and its debts regarding the resolution of the problem of psychiatry in Argentina. However, new social assistance institutions of vulnerable groups were created that were parallel to the offers of the first private psychiatric hospitalization services: the Frenopáticos Institutes. While the poor crazy people had to go to abandoned public institutions, those with economic resources could access places of greater comfort and convenience. In Argentina, mutual organizations had passed in the decades from 20 to 40 , grouping by nationality of origin, the order by branch of production, linked to the respective trade union organizations. These mutual organizations, formed by the unions on the basis of voluntary association, had been encouraged from the political power, during the period 1945-55. For this reason, gradually they went from voluntariness to compulsory, through Collective Labor Agreements. In such a way that, towards the end of the 1950s, the expectation grew that they would constitute the institutional basis of an integral Social Security system. Although they were created with broad objectives of social assistance (own clinics, supply stores, vacation camps, leisure fields, housing plans), from that moment the government policy will assign them as a nuclear mission, finance medical care under the generic name of Social Works.

Since the 40s, the Welfare State in Argentina, with a populist characteristic, was consolidated through the emergence and consolidation of Peronism. The creation from the state of union bureaucratic organizations that begin to administer the newly born social works, culminated, for Carpintero (2011), in the alliance of this new actor in the field of health with psychiatric psychiatrists in their defense of the asylum device [12]. The health minister from 1946 to 1952 was the neurologist Ramón Carrillo. In mental health, he tried to give material solutions to problems such as the lack of hospital capacity and coordination between different 


\section{Psychology \& Psychological Research International Journal}

jurisdictions responsible for the treatment of madness. In this way new places of attention were reformed and inaugurated, such as the new Hospices built by pavilions. In the field of psychiatry it was controversial. On the one hand he found support in the nationalist psychiatrists of the Hospitals and Colonies, especially in the Hospice of Men. These, together with the union bureaucrats, were the ones who threw Enrique Pichón Rivière out of the hospital accusing him of being a "communist" and of "promoting homosexuality" for having started to implement therapeutic groups with patients. But the medical guild and most of the psychiatrists linked to Hygienism did not support Carrillo's reforms. For the author, in those years of the Peronist government the deterioration of the situation in the asylums remained.

In our country, in the mid-fifties the tasks to be carried out were enormous due to the disastrous conditions of the hospices. During the year 1957, in Argentina, with the imposition of developmentalism as an economic, political and social strategy in the period of the Frondizi government and during the dictatorship of Onganía, three decisive events took place to reaffirm in our country the "health field" mental":

1. The National Institute of Mental Health is created.

2. Dr. Mauricio Goldenberg founded the first psychopathology service at the General Hospital of Lanús, that is, outside a psychiatric hospital

3. a career in Psychology is created at the Faculty of Philosophy and Arts of the UBA. It was not only the psychiatrist who was solely responsible for mental health, other actors also appeared, especially psychologists who, despite having severely limited clinical practice, were gaining important spaces in hospitals and mental health centers, although in many cases should work for free. The conceptualizations of Psychoanalysis, sociology, anthropology, institutional psychology and community psychiatry began to take an interest in the reality of the asylum institutions with a critical look that emphasized the need to deploy community and preventive-care practices. During these years, the first mental health residences, the inpatient rooms in general hospitals, the day hospitals and the therapeutic communities were created. At the same time, the therapeutic approaches that showed the potential benefits of extending the limits of psychoanalysis were disseminated: group, family and institutional treatments, psychodrama, social psychology and children's psychoanalysis. However, the asylum structure remained in force supported by the different political powers that go through the decades of the '60s and' 70 s, which prohibited and repressed some experiences. The reforms of this era have remained as testimony of partial experiences that were not integrated into a National Mental Health plan. The 1976 civic-military dictatorship finally installed State Terrorism. Mental health services are destroyed as the institutions were intervened by a civic-military bureaucracy within the framework of a project aimed at carrying out the National Security Doctrine. At this moment, a determined privatist policy in the field of health begins to take hold. That is, if until now the State had disregarded Mental Health; private groups begin to take power to put the field of Mental Health at the service of their economic interests.

When the democratic transition period begins in the early eighties, we try to generate a Mental Health policy to recover the spaces destroyed by the dictatorship. From the perspective of Primary Health Care, experiences such as the Pilot Plan for Mental and Social Health (La BocaBarracas) are carried out, which are quickly exhausted due to the lack of an adequate budget and a political decision to continue them. Once again, it starts with pilot plans that end shortly after not having the support of the State. In this sense, Enrique Carpintero (2011) emphasizes that the history of our country is the history of pilot plans and the continuity of asylums since the end of the 19th century. The greatest achievement, at this time, was the antimanicomial reform carried out in the Province of Río Negro.

Finally, in the '90s a capitalist neoliberal policy governed by deregulation, privatization and competition was reaffirmed. Health is mainly in the hands of the market. That is, the big laboratories and medicine companies. As Maitena María Fidalgo (2008) points out [13]: "The general panorama of the health sector shows an acute crisis of social security, discredited and underfunded; a public sector that maintains a stable budget in the face of increasing demand; a private sector that meets the needs of sectors with certain purchasing power, fragmenting, and differentiating health plans according to the ability to pay. Thus, the health sector was consolidated as another market, radicalizing the distributive bid that had been registered for decades ". Its consequence is a righting of the management of social crises that will modify the rules of the game in the field of health policies. The State disappears in its social function of serving public health to serve private interests. In this way, the dismantling of public institutions takes place since health is in the hands of the private initiative whose computer axis is the cost-benefit ratio. The process of capitalist globalization brings with it the exclusion and 


\section{Psychology \& Psychological Research International Journal}

disaffiliation of large sectors of the population that are thus displaced to the margins of society.

\section{Discussion and Conclusion}

Thus we find the National Mental Health Law No. 26627, enacted on November 25, 2010 and promulgated in December of the same year, and it is from this that a framework of reference in the change of old practices is generated socio-sanitary and hospitalization of the nineteenth century [14]. On the other hand, in said Law, Article 3 recognizes Mental Health "as a process determined by historical, socio-economic, cultural, biological and psychological components, whose preservation and improvement implies a dynamic of social construction linked to the concretion of the human and social rights of every person."(Argentina Mental Health Law, 2010, page 9) It can be seen how the theoretical conception that underlies the Primary Health Care practices of Mental Health, rests on a bio- psychosocial, where the psychic appears as parallel to the organism that suffers the consequences of the environment or external factors and biological factors. The National Mental Health Law has installed an indispensable public debate regarding the protection of civic, social and cultural rights in the care of the mentally ill. In addition to its relevant symbolic dimension, the law expresses a decided social will to transform a field of practices that, furrowed by political tensions of very diverse type, has been raised highly refractory to change and in which the violation of the rights has been historically naturalized. human rights of the people assisted. One of the issues that has favored the new paradigm in mental health is linked to the revision of the traditional assumptions of ethics applied to health from the emergence of a perspective based on the principles of autonomy, dignity and equity Social.

For Carpintero (2011), the political context that enables the enactment and enactment of the law is precisely that of the advance of the globalization of the market economy [12]. In this regard, the author points out that the high costs of hospitalization of large asylums would be the primary driver of the recommendations of international organizations such as WHO or PAHO on the deinstitutionalization of mental health. The Right to the Protection of Mental Health Law is the first legal norm that gives a national framework to the policies in the area. As Ana Hermosilla and Rocío Cataldo point out, "it inaugurates a period of changes, of revision of practices and conceptions that, up to now, have supported the attention of those with mental illness". (2012, p. 134) Among the main innovations, are:

- The emphasis placed on interdisciplinarity, which should characterize the practices of the teams. It is equated to the members of the same in relation to decision making and the possibility of occupying positions of management and direction of services. Even psychopharmacological treatments are planned within the framework of interdisciplinary approaches.

- Community orientation, intersectoral work and the requirement of informed consent for patient care are established.

- Provisions regarding hospitalizations: they become the last therapeutic resource, of a restrictive nature. Therefore, the care process should preferably be carried out outside the scope of hospitalization. In relation to the international issue, the creation of new asylums is prohibited. In turn, existing ones must be adapted to follow the principles set out in the Law, until their definitive substitution by alternative devices: cohabitation houses, day hospitals, work cooperatives, socio-labor training centers, social enterprises, homes and families substitutes.

- In reference to the impact on Argentine law, it modifies the Civil Code by eliminating the concept of danger and replacing it with that of a certain and imminent danger as a criterion for involuntary commitment. (Carpenter, 2011) The main criticisms formulated to the Law of Mental Health have pointed to the academic preparation of those who arrange the hospitalizations and externalities, to the imprecision in the definition of the object, to the risk of a definitive and premature closing of the monovalent institutions, to the viability of the law and interdisciplinarity as a muddy practice of scarce feasibility. On the contrary, in relation to valid criticisms, it can be said that they put on the table the problem (and challenge) of delimiting a professional training that allows to establish a precise and consistent concern in each case, the problem of budgetary resources that become operative the law and the question of the importance of clinical specificity in relation to the definition of the object of the Mental Health Law. It is important to underline an affirmation included in Article 3 of the Law, dedicated to the definition of Mental Health. The statement to which I refer is the following: "It must be based on the presumption of capacity of all people." (National Mental Health Law, 2010) This idea is perhaps the main axis of the Law [14]. 


\section{Psychology \& Psychological Research International Journal}

A few years after the formulation of the Strategy and Plan of Action on Mental Health that the Ministers of Health of the Americas approved in the Assembly of the Pan American Health Organization (PAHO / WHO) of August 2009, and 6 years after enactment of the National Mental Health Law, the field of Mental Health in Argentina today has a multiplicity and heterogeneity. This speaks of the fact that, although progress has been made with respect to legislation and with regard to the intentions of reforming the care of those with subjective suffering, there are evident shortcomings in the planning, management and formulation of programs. That optimizes, distribute and give coherence to the system. In addition, there is many times another big gap, which few dare to jump.

This is the one that opens between the formulation of Mental Health policies and the demands of a clinic that supports the responses that professionals in the field offer to subjective suffering. Another important point to place is the complex relationship established with the policies and practices of Primary Health Care, that is, the complexity of the relationships of those who manage, work, plan in Mental Health with those who do it from the field of health. Health in general. We also observe that for the same diversity of disciplines, practices and problems that constitute the domain of Mental Health, it is forced to rehearse options of interdisciplinarity and transdisciplinarity both when it comes to developing strategies, and when it comes to the creation of alternative devices to the already perimida practice of enclosure of the asylum. Finally, the time in which we live has modified and expanded the landscape of demands to the mental health system, which merits from the public health field the survey of new problems as well as the production of work tools to give effective answers (which expected).

And as we have mentioned, it is from the perspective we have been developing that political power, linked to the process of capitalist globalization, is not interested in continuing to maintain large asylum structures. For this reason, international organizations such as WHO and PAHO recommend the deinstitutionalization of Mental Health. It is in this context that we place the sanction by the House of Senators and Deputies of the Nation, of the National Mental Health Law $\mathrm{N}^{\circ}$ 26657. Law that raises in its articles some questions whose importance implies a rupture with the operation of the manicomial order in Argentina and sustains fundamental Human rights of the patients.
We consider important then to analyze what has happened in the history of public policies on mental health because even when there is widespread consensus in the scientific community regarding the need to give such problems an integral, complex and focused on the historical-social dimension, the hegemonic orientation in the formation of human resources and the practice of health services continues to be individualistic, fragmented, reductionist and apart from the social. As a consequence of the primacy of this approach, assistance programs are often organized according to a sectoral logic in which the targeting of the recipients and the fragmentation of actions are the most important, which is expressed directly in the difficulty of coordinating objectives, resources and actions between technical areas that respond to different dependencies of the State apparatus itself. This fragmentation reproduces a segmented logic that hinders the articulation of the practices that professionals perform in each of the institutions included in these programs and reinforces some limitations inherent to public policies, among which the conception of users as recipients should be noted. Liabilities of the assistance dispensed [15].

It should be noted that the focus of psychology, our profession, a discipline traditionally excluded from all the knowledge that has operated in the field of care of the disease, has unquestionable potential to add its contribution from a perspective that highlights the salutogenic potential of the individuals and communities and not merely actions of assistance or repair of the disease. We can place this contribution in the framework of what is currently called healthy public policy. In this way, the central objective is to analyze and historicize the material and symbolic obstacles, and the different spaces of participation that limited, enabled and / or guaranteed the right to a comprehensive care of mental health care.

\section{References}

1. Stolkiner A (2009) Ethics and practices in Mental Health. In Bioethics, Mental Health and Psychoanalysis. Compilers Juan Carlos Fantin and Pablo Friedman. (pp. 171-186). Buenos Aires. Editorial Polemos.

2. Arriaga M, Ceriani L, Monopoli V (2013) Public policies on mental health: from a protective paradigm to one of human rights. By the Ministry of Justice and Human Rights of the Nation. Secretariat of Human Rights. 


\section{Psychology \& Psychological Research International Journal}

3. Foucault M (1967) History of Madness in the classical era. Fund of Economic Culture. Mexico. 2010

4. Galende E (1990) Psychoanalysis and Mental Health. For a critique of psychiatric reason. Buenos Aires. Paidos

5. Kanner L (1971) Child Psychiatry Buenos Aires. Paidos.

6. Stolkiner A (2003) New approaches in mental health. Lecture at the XIV Latin American Architecture and Engineering Congress. Buenos Aires.

7. World Health Organization (1948) Constitution of the World Health Organization.

8. Federal Health Council (2004) Bases of the Federal Health Plan 2004-2007. Buenos Aires. Ministry of Health of La Nación.

9. World Health Organization (1978) Declaration of Alma - Ata. WHO.
10. Galende E (1992) Perspectives on Mental Health in Argentina for the next decade. FLACSO-OPS Seminar. Buenos Aires.

11. Falcone R (2013) History of the practices of psychology, psychiatry and psychoanalysis. Results of the investigation from clinical cases (1900-1960). In research yearbook. Vol. XX. No. 2 National University of Buenos Aires.

12. Caprintero E (2011) The subjectivity besieged. The medicalization to domesticate the subject. Imperfect Future Series. Fichas for the 21st century. Editorial Topía.

13. Fidalgo M (2008) Goodbye to the right to health. Buenos Aires. Editorial space.

14. National Argentine Law of Mental Health (2011) Ministry of Health of the Argentine Nation.

15. De Lellis M (2010) Psychology and healthy public policies. In Psience. Latin American Journal of Psychological Science 2(2). 